International Journal of Agriculture, Environment and Bioresearch

Vol. 4, No. 06; 2019

ISSN: $2456-8643$

\title{
TRIOZA SCHEFFLERAE SP.NOV. (HEMIPTERA: TRIOZIDAE), A NEW SPECIES OF PSYLLID ASSOCIATED WITH SCHEFFLERA ABYSSINICA (ARALIACEAE) FROM CAMEROON
}

\author{
Yana Wenceslas ${ }^{1,2 *}$, Dzokou Victor Joly ${ }^{2,3}$, Mveyo Ndankeu Yves Patrick ${ }^{2,4}$, Douni Goune Vanissa Sonia ${ }^{1}$, and \\ Tamesse Joseph Lebel ${ }^{2}$ \\ ${ }^{1}$ Laboratory of Biological Sciences, Faculty of Sciences, University of Bamenda, P.O. Box 39 Bambili, Cameroon, \\ Tel: 00237675629251 \\ ${ }^{2}$ Laboratory of Zoology, Higher Teacher's Training College, University of Yaounde I, P.O. Box 47 Yaounde, \\ Cameroon, Tel: 00237677522850 \\ ${ }^{3}$ Laboratory of Agricultural Zoology(UR_PHYZA), Faculty of Agronomy and Agricultural Sciences, Department of \\ Plant Protection, University of Dschang, P.O. Box. 222 Dschang, Cameroon, Tel: 00237698710070 \\ ${ }^{4}$ Laboratory of Zoology, Faculty of Sciences, University of Yaounde I, P.O. Box 812 Yaounde, Cameroon, Tel:
} 00237695032267

http://doi.org/10.35410/IJAEB.2019.4475

\begin{abstract}
Psyllids are phloem feeding insects which induce damages to their host plants. Few number of psyllid species has been described in Cameroon and many species remain unknown. Recent field survey carried out in Cameroon, permitted to collect Trioza schefflerae sp. nov. on Schefflera abyssinica (Araliaceae) a valuable timber tree on which it causes serious damage by inducing pit galls and leaf necrosis. Adult were captured with a sweep net of $0.5 \mathrm{~mm}$ mesh size and an aspirator while the larvae were sampled directly on the host plant at Titia locality, West, Cameroon. Drawings and measurements were made from slide-mounted material. The nymph margins covered by truncate tubular sectasetae; circumanal semi-circular. Adult, genal cones developed with rounded apices; male genitalia with a pedunculate proctiger, paramere slightly narrow apically; aedeagus presents a sickle-shaped apical inflation with a sclerotized end tube of ductus ejaculatorius; female genitalia with a trapezoidal proctiger bearing medial long setae; subgenital plate triangular with a rounded apex. Trioza schefflerae is closely related to T. valida from Taiwan but the two species differ on the shape of head, antenna, wings, and female genitalia. Then T. schefflerae is a new species of psyllid in Triozidae family.
\end{abstract}

Keywords: Taxonomy, Trioza, pest, Schefflera, Cameroon.

\section{INTRODUCTION}

Schefflera abyssinica is indigenous plant well distributed to the mountains of the West region of Cameroon. It belongs to Araliaceae family. Schefflera abyssinica is used by bees to produce honey. It is also used locally by the people of West region of Cameroon to treat small pox. The wood is used to produce furniture, boxes, water pots and agriculture implements by the local population. Schefflera abyssinica is associated with a species of psyllid (Trioza) of the Triozidae family which is caused damages to the host plant. The adults sucking the sap of the host plant and the larvae induce the pit galls on the lower face of leaves sometime causing their necrosis. According to [1], psyllids are phloem feeding insects with a high degree of specificity towards 
their host plant. According to [2], they are usually associated with Dicotyledons. Few number of psyllid species has been described in Cameroon and many species remain unknown. Concerning the Triozidae family, the first taxonomic work was carried out by [3]. He described 68 species of afrotropical regions and 14 species were from Cameroon; 7 species of Trioza genus and 7 species of Pauropsylla genus. Later [4] recorded 35 species in which 11 species of Pauropsylla genus and 24 species of Trioza genus. Among the 35 species recorded, 13 species of Trioza genus and 4 species of Pauropsylla genus were not described. Trioza messii associated with Caloncoba welwitschii (Flacourtiaceae) was described by [5]. Recently [6] described Trioza kala associated with Beilschmiedia obscura (Lauraceae). According to the above information for the taxonomic of Triozidae in Cameroon, many species remain not described like the psyllid of $S$. abyssinica of the Trioza genus. According to [3], psyllids of Trioza genus are characterized by the fifth instar larvae of most species with the head and body margins have a complete fringe of specialized wax-producing setae called sectasetae; in adults the forewing shape is mostly elongate ellipsoid and narrowing to a subangular apex, but if the apex is rounded, it is 2-3 times longer than wide; radular areas are present only in cells $m_{1}, m_{2}$ and $\mathrm{cu}_{1}$; claval suture reaching hind margin of wing some distance from apex of $\mathrm{Cu}_{1 b}$; basal tarsal segment of hind leg without apical spurs; male proctiger unipartite.

\section{MATERIALS AND METHODS}

Locality where specimens were collected: locality of Titia, Menoua Division, West Region of Cameroon (latitude: $05^{\circ} 26^{\prime} 38^{\prime}$ 'N, longitude: $10^{\circ} 04^{\prime} 11^{\prime \prime} \mathrm{E}$, altitude: $1385 \mathrm{~m}$ ).

Type series deposit: the specimens Trioza schefflerae sp. nov. collected were deposited in the collection of the Laboratory of Zoology, Higher Teacher's Training College, University of Yaounde I (LZUY), and the Laboratory of Agricultural Zoology, Faculty of Agronomy and Agricultural Sciences, University of Dschang (LAZUDs).

Field survey: the observations and survey took place in Titia locality from August, 2017 October, 2017. During the field survey the host plant was inspected, adult psyllids were captured with a sweep net of $0.5 \mathrm{~mm}$ mesh size and mouth aspirator. Larvae were sampled directly from buds and leaves of the various host plants. The host plant was collected and was identified at National Herbarium of Yaounde (NHY). These identified host plants were deposited in LZUY).

Observations and illustrations: the specimens are preserved dry and slide-mounted or in $70 \%$ ethanol and are deposited in LZUY. Morphology of fifth instar larva and adults was illustrated using transmission Leica Microscope and measurements were made from slide-mounted using Leica Stereomicroscope.

Terminologies: morphological terminology used to describe Trioza schefflerae sp. nov. follows the identification keys of [3]- [7]- [8]; [9]. The following terms were used: vertex, occelus, genal cone, flagellomere, rhinarium, forewing, pterostigma, rmcrossvein, punctiform, hindwing, costal break, meracanthus, genual spine, saltatorial spurs, arolium, male genitalia, male proctiger, paramere, aedeagus, ejaculatory duct, female genitalia, female proctiger, subgenital plate, circumanal ring.

\section{RESULT}

\subsection{Fifth instar larva}


Colouration: Overall body is yellowish; the dorsal side of abdomen carries two dark bands which indicating the pattern of abdominal tergites.

Structure: Final instar larva (fig.1) is flattened and about 1.4 times longer than wide. The head, thorax and abdomen are not clearly separated. Antenna is short with 10 segments; flagellum carries a single subapical rhinarium on flagellomeres 1,3 , and 5; the fifth flagellomere bears single simple subapical seta and the antenna ends by a long subapical seta and short truncate apical seta (fig.2). The legs bear few minute simple lanceolate setae while the margins of the body and wing pads are covered by truncate tubular sectasetae. The metathoracic leg ends by a sessile globular tarsal arolium (fig.3). Caudal region of abdomen carries a semi-circular circumanal with a deep groove on the apical side and composed of one ring of elongate pores. Measurements and ratios are found in table 1

\subsection{Adult}

Colouration: Overall body is yellowish for female and reddish for male but the thoracic and abdominal tergites are dark brown. The vertex is divided by a midline which is dark brown and the both medial portions of the vertex are clear without the setae while the lateral portions are dark brown with short setae. Forewings are slightly smoked while the hindwings are transparent. Structure: the head (fig.4) slightly narrower than mesonotum in profile is weakly inclined from longitudinal body axis at a $45^{\circ}$ angle; the vertex is 1.3 times longer than wide. Lateral ocelli are oval and placed posteriorly on vertex while the median ocellus is round and placed anteriorly on the vertex. Genal cones are well developed with rounded apices; they are sparse by simple lanceolate setae. Antennal sockets enlarged; antennal flagellum is 2.1-2.3 times longer than head width (fig.5). The two first antennal segments bear short setae; the first flagellomere is the longest antennal segment and bears two subapical setae; a single simple subapical rhinarium is carried on flagellomeres 2, 4, 6 and 7; each rhinarium is surrounded by setae except the one of flagellomere 7; the last flagellomere bears a long subapical seta and a short apical seta. Thorax strongly arched; the pronotum is narrow and arcuate medially; the mesonotum is large and the mesopostnotum small; mesonotum is composed of mesopraescutum which is slightly arched, mesoscutum and mesoscutellum which are trapezoidal; the metanotum is composed of the metascutum (small) and the metascutellum (large) and metapostnotum which is relatively large and trapezoidal and is completely fused with the first abdominal tergite. Forewing (fig.7) hyaline, elongate oval and narrowing subacute apex, forewing is 2.4-2.6 times longer than wide; veins without setae; vein $\mathrm{R}+\mathrm{M}+\mathrm{Cu}$ is strictly trifurcating; vein $\mathrm{R}$ was short about 0.24 times as long as $\mathrm{Rs}$ vein; vein $\mathrm{Cu}_{1 \mathrm{a}}$ was 2.5 times as long as $\mathrm{Cu}_{1 \mathrm{~b}} ; \mathrm{Cu}_{l}$ cell more wide than higher; radular spinules forming narrow stripes in cells $m_{2}$ and $c u_{l}$ but on $m_{l}$ cell the radular spinule is large at the basis and ending narrow; forewing 1.7 times longer than hindwing. Hindwing (fig.8) with grouped costal setae: 3 setae before costal break, 4 setae plus 5 setae and hamelus after the costal break $(3+4+5+1)$; hindwing 3.5 times longer than wide. The metathoracic leg (figs.9, 10) is long with long metacoxa carrying a short acute and pointed meracanthus; metatibia without basal spine, apical spurs of metatibia arranged as one outer and three inner spurs $(1+3)$; arolium is globular; the metatibia leg is sparse by simple lanceolate setae. Male genitalia, as in (fig.11), shows a triangular subgenital plate with simple lanceolate setae. Proctiger is peduncular with a subapical expanded internal margin; it is sparse by simple lanceolate setae. Paramere (fig.12), is straight slightly narrow on the apical portion, apex sclerotized; the paramere is arched on the 
external margin and sparse by simple lanceolate setae. The distal portion of aedeagus (fig.13), is relatively short about 0.5 times as long as the proximal portion; the distal portion of aedeagus presents a sickle-shaped apical inflation with a sclerotized end tube of ductus ejaculatorius relatively long and thick.. Female genitalia as in (fig.14); in profile is relatively short, dorsal outline of proctiger beyond circumanal ring; the proctiger is trapezoidal with narrow apical portion and rounded apex; the medial portion bears long simple lanceolate setae; circumanal ring is composed of two row of elongate pores. The subgenital plate is triangular with a tapering apical portion and rounded apex; it is covered moderately by short simple setae. The ovipositor is well developed; lateral valvulae bluntly rounded apically; dorsal and ventral valvulae are straight. Measurements and ratios are found in table 2.

\section{Material examined}

Holotype $\widehat{\jmath}$ : Titia, Menoua Division, West Region of Cameroon; latitude: 05²6'121"N, longitude: $10^{\circ} 04^{\prime} 004^{\prime \prime} \mathrm{E}$, altitude: $1385 \mathrm{~m} ; 8$ viii 2017 (LZUY).

Paratype: Titia, $05^{\circ} 26^{\prime} 121^{\prime \prime} \mathrm{N}$; $10^{\circ} 04^{\prime} 004^{\prime \prime} \mathrm{E} ; 1385 \mathrm{~m}: 8$ viii 2017; $10{ }^{\lambda}, 15$ q, 4 larvae; 12 viii 2017, 23त̄, 27우, 12 larvae; 24 viii 2017, 10 $\overbrace{}^{\lambda}, 1$, 4 larvae (LZUY).

Etymology: the species name refers to its host plant Schefflera abyssinica.

\section{DAMAGES CAUSED BY TRIOZA SCHEFFLERAE ON THE HOST PLANT: SCHEFFLERA ABYSSINICA (ARALIACEAE)}

Trioza schefflerae sp. nov. causes similar damages with other triozid species to its host plant, but with some particularities. The larvae are found on the lower side of the young leaves, buds, flowers, and fruits where they induce the pit galls. These pit galls become closed to confine the larvae and the older galls open on upper side of the leaves to liberate the imagos. Generally each gall carries more than one larva few number of galls carry single larva. The young strongly attacked leaves and buds become stunting. The proliferation of the larvae and adults induces necrosis of the leaves and buds (fig. 15). The larvae also produce white wax that can induce the growth of fungi. The attacked fruits holding the larvae change form and colour which become irregular form and clear than the non attacked fruits which were green colour and rounded form. The female, male and larva of Trioza schefflerae sp. nov. preserved in $70 \%$ of ethanol are presented in figures 16,17 , and 18.

\section{DISCUSSION AND CONCLUSION}

Trioza schefflerae sp. nov. share with T. valida described in Taiwan by [10], the male proctiger, paramere, distal segment of aedeagus and male subgenital plate shapes; but T. schefflerae sp. nov. differs from $T$. valida in details of the distribution and size of setae on proctiger, paramere and subgenital plate. For example the proctiger of the former bears short setae on the surface, on the dorsal margin long simple lanceolate setae are grouped as $2+4+4$ from medial portion to distal portion; ventral margin with three isolated long setae while in the latter long simple lanceolate setae are distributed on the surface, dorsal and ventral margins. Paramere inner margin of the former bears densely long simple setae and the outer margin lacks setae while in the latter inner and outer margins bears relatively long simple setae. The female genitalia of the two species is similar but it is short in the former and long in the latter; the circumanal of the former 
is large with two rings of pores while in the latter the circumanal is narrowed with a single ring of pores. Trioza schefflerae sp. nov. differs from T. valida as follows: in the former the head is slightly narrower than the thorax, vertex is divided by a midline which is dark brown and the both medial portions of the vertex are clear without the setae while the lateral portions are dark brown with short setae, vertex is 1.3 times as long as wide; while in the latter the head is wider than thorax vertex 1.8 times as wide as long and entirely sparse by short setae. Genal cones are well developed with rounded apices in T. schefflerae sp. nov. while in T. valida genal cones are broad and stout distinctly shorter than vertex, strongly divergent and pubescent, blont at apex. Forewing in the former is elongate oval and narrowing subacute apex, it is 2.4-2.6 times longer than wide, veins without setae while in the latter forewing is long narrowed at base, angulate at apex, 2.4 times as long as wide, veins prominently setiferous at basal half. Also the head and forewing of $T$. schefflerae sp. nov. are similar to T. quadrimaculata from Taiwan described by [10], except that the vertex of the latter presents stripe and lacks setae. Trioza schefflerae sp. nov. and T. pitformis from India and Taiwan described by [10], share female genitalia and forewing shape but differ in details of the structure of circumanal which is large in the former and narrowed in the latter; female proctiger bears several long setae medially in the former while in the latter there is a pair of long setae. Trioza schefflerae sp. nov. differs from T. kala described by [6] in the genal cones which are not well developed with divergent apices rather than welldeveloped genal cones with rounded apices; first flagellomere of the former lacks rhinaria while in the latter first flagellomere carries many rhinaria; the distal portion of aedeagus of the former presents a sickle-shaped apical inflation while in the latter there is no apical inflation.

\section{ACKNOWLEDGMENTS}

We thank Proffessor Bonaventure Sonke of the Yaounde I University for the identification of the host plant. 
International Journal of Agriculture, Environment and Bioresearch

Vol. 4, No. 06; 2019

ISSN: $2456-8643$

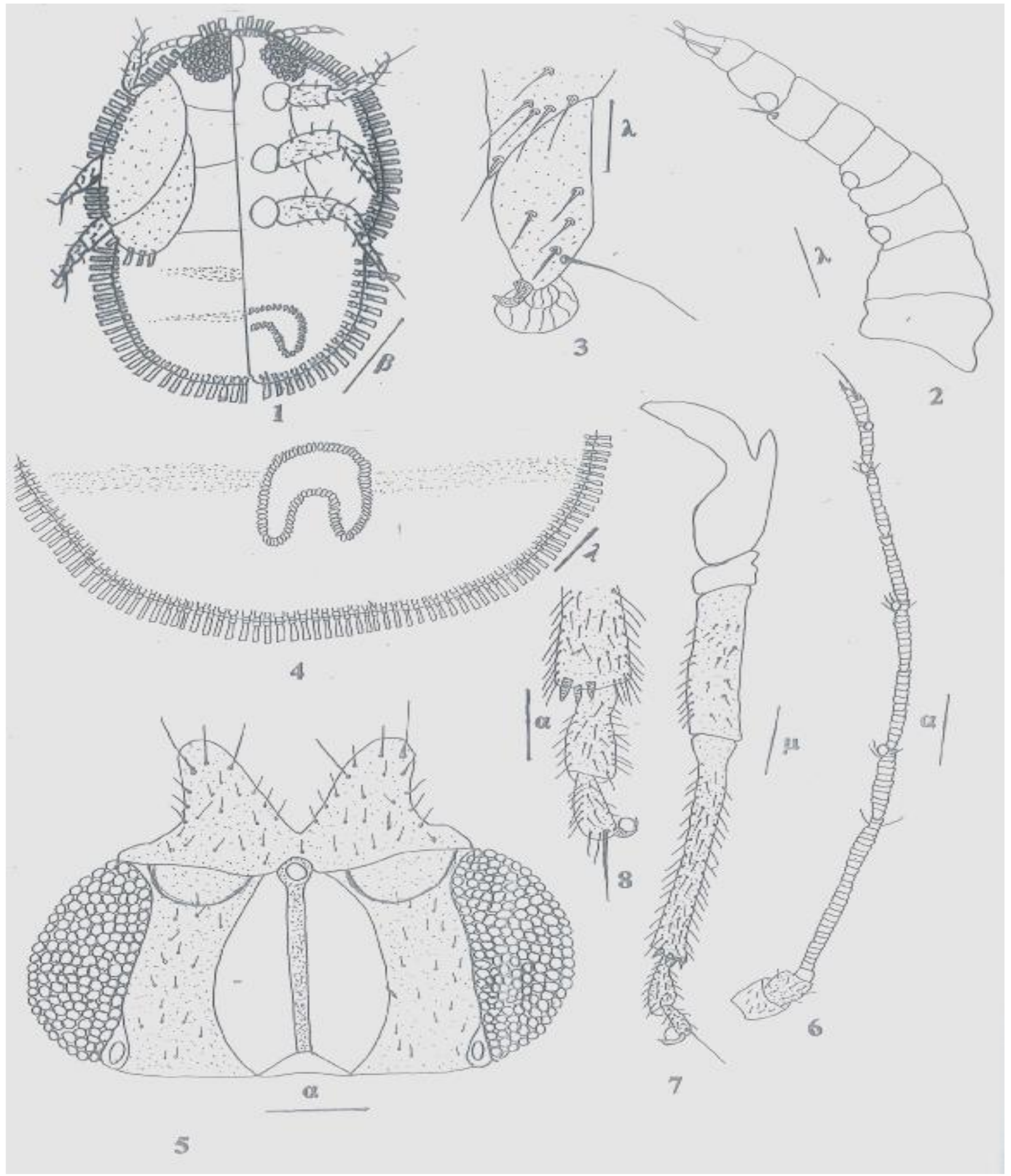

Figures 1-8: Trioza schefflerae sp. nov.: 1, fifth instar larva, dorsal view (right), ventral view (left); 2, larval antenna; 3, tarsal apex with claws and arolium; 4, ventral view of larval apical 
International Journal of Agriculture, Environment and Bioresearch

Vol. 4, No. 06; 2019

ISSN: $2456-8643$

abdomen; 5, adult head dorsal view; $\mathbf{6}$, adult antenna; $\mathbf{7 , ~} \mathbf{8}$, adult hind leg. Scale bars: $\lambda=0.06$ $\mathrm{mm} ; \alpha=0.12 \mathrm{~mm} ; \beta=0.4 \mathrm{~mm} ; \mu=0.24 \mathrm{~mm}$.
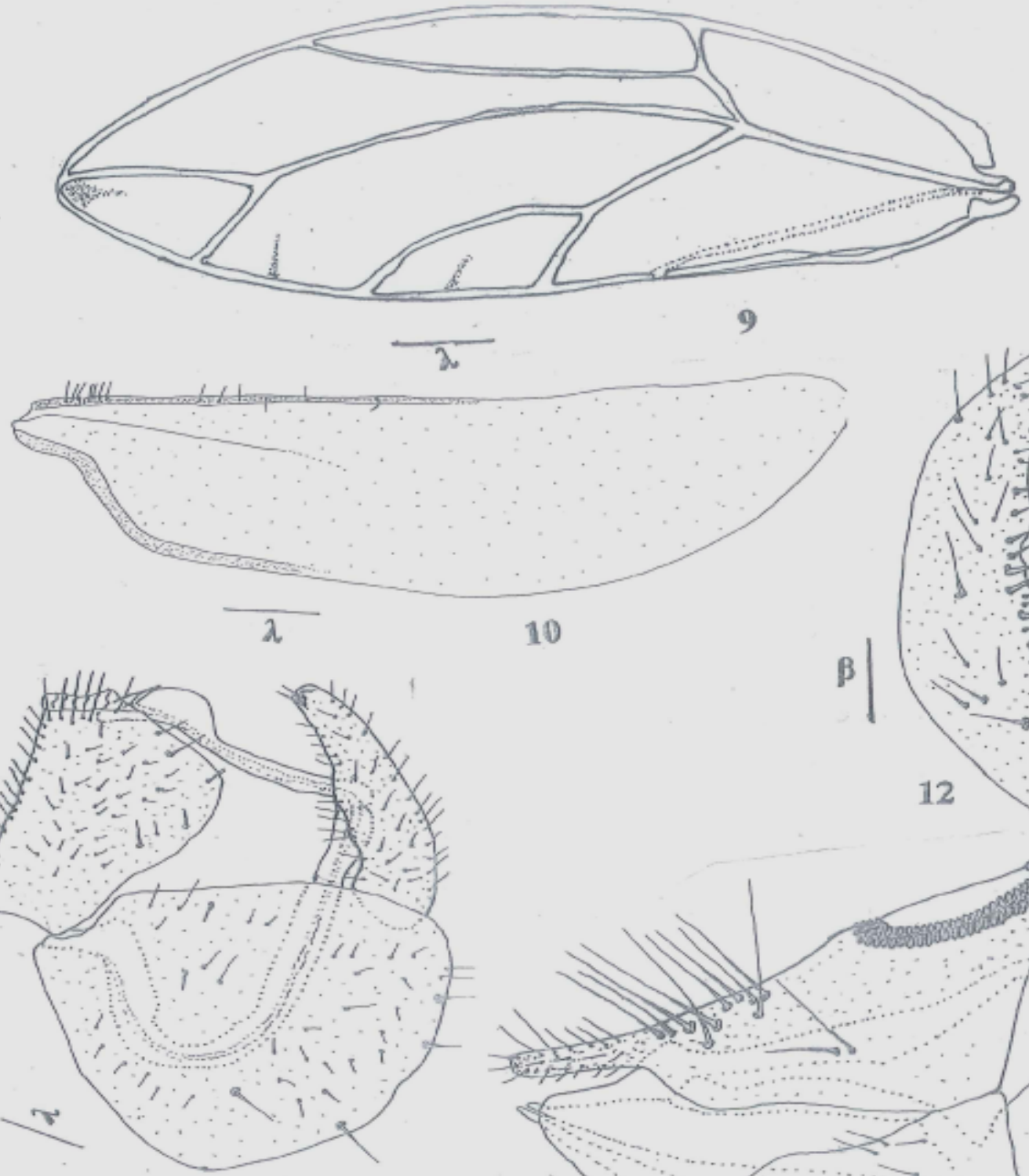

11
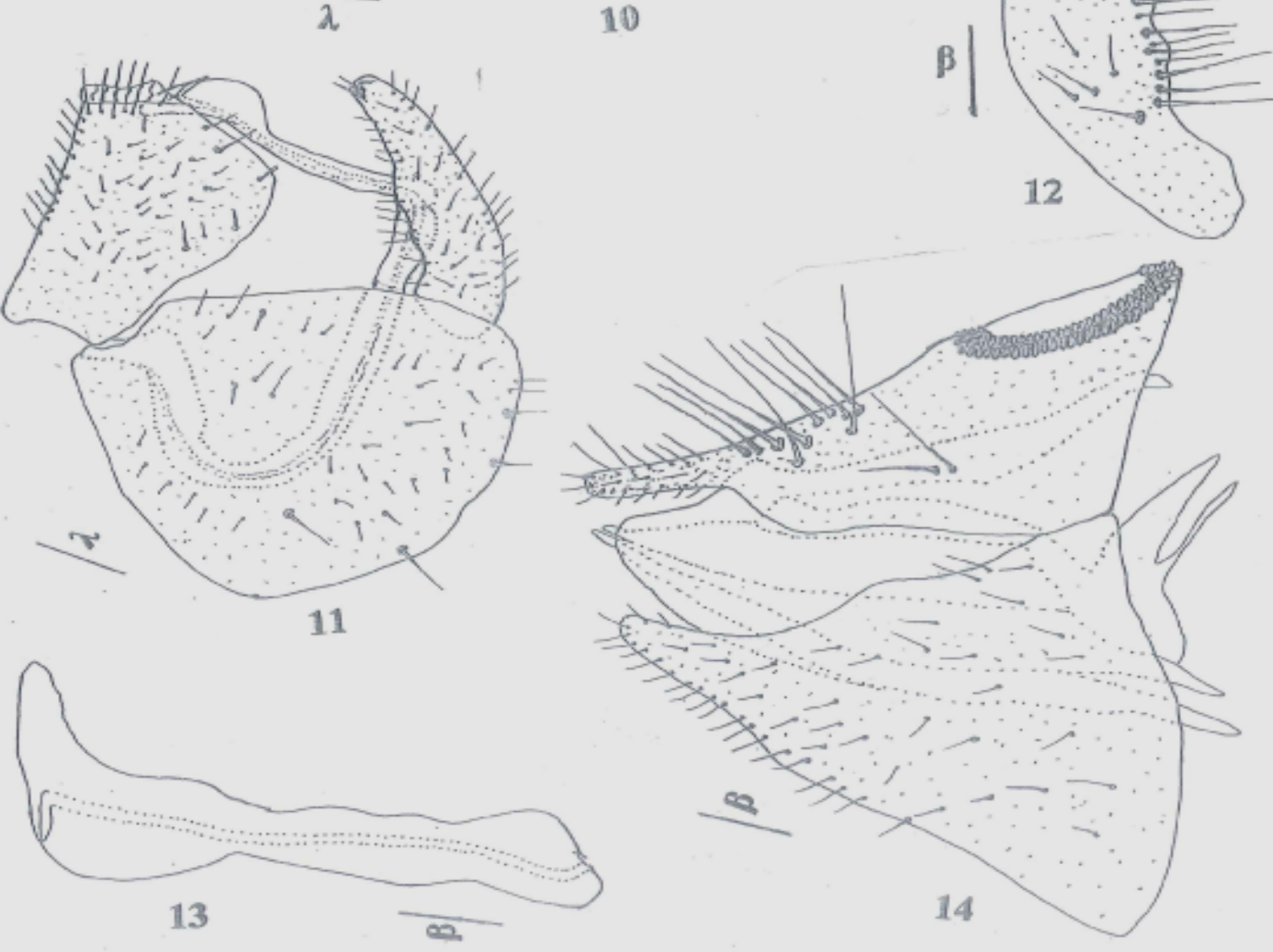
Figures 9-14: Trioza schefflerae sp. nov.: 9, adult forewing; 10, adult hindwing; 11, male genitalia in profile; 12, paramere in lateral view; 13, distal portion of aedeagus; 14, female genitalia in profile. Scale bars: $\lambda=0.16 \mathrm{~mm} ; \beta=0.04 \mathrm{~mm}$.

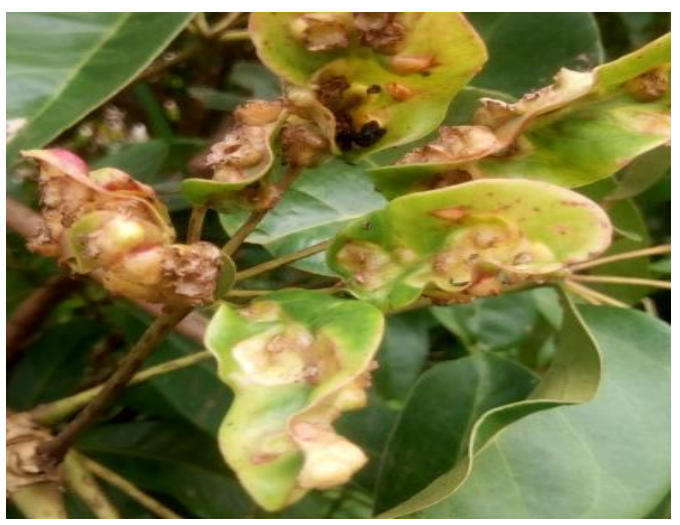

Figure 15: pit galls on the leaves of Schefflera abyssinica caused by Trioza schefflerae sp. nov.

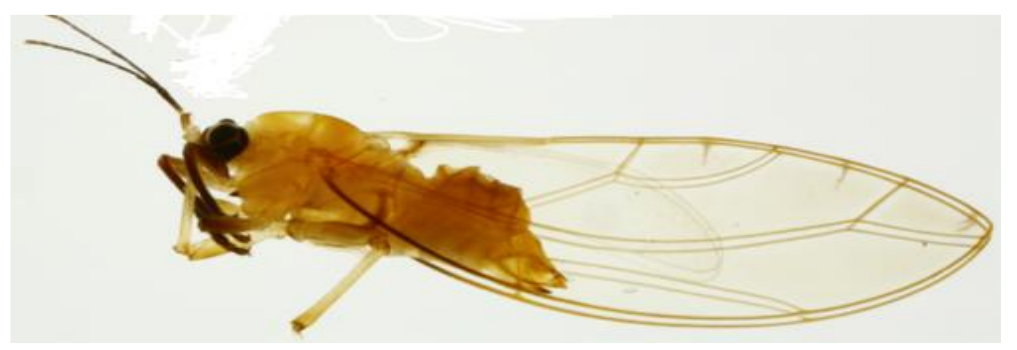

Figure 16: Trioza schefflerae sp. nov. female

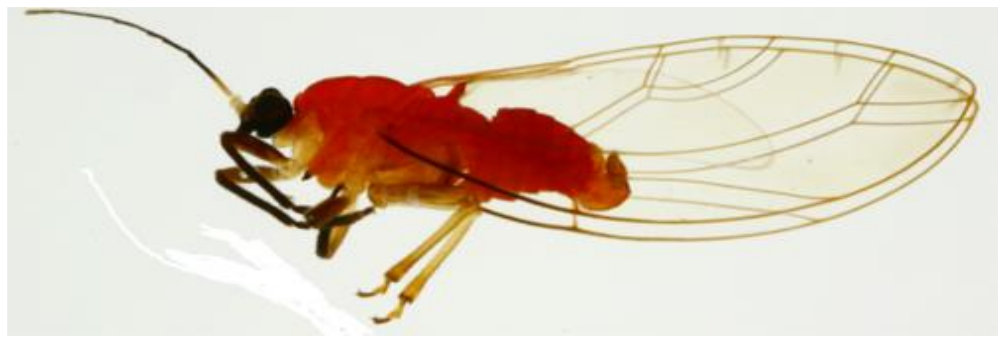

Figure 17: Trioza schefflerae sp. nov. male

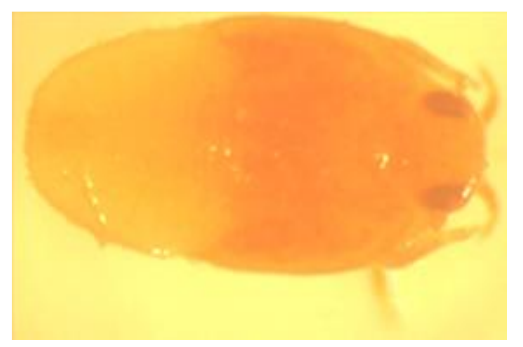


Figure 18: Trioza schefflerae sp. nov. fifth instar larva

Table 1: Measurements $(\mathrm{mm})$ of Trioza schefflerae nymphs $(\mathrm{N}=$ number of measured specimens)

\begin{tabular}{|lllll|}
\hline Parameters & N & Minimum & Maximum & Average \\
BL & 20 & 1.82 & 2.52 & 2.25 \\
BW & 20 & 0.23 & 0.64 & 0.46 \\
AL & 20 & 0.17 & 0.47 & 0.30 \\
MTL & 20 & 0.29 & 0.58 & 0.43 \\
WL & 20 & 0.73 & 1.11 & 0.98 \\
\hline
\end{tabular}

Abbreviations: $\mathbf{B L}=$ body length; $\mathbf{B W}=$ body width; $\mathbf{A L}=$ antenna length; $\mathbf{W} \mathbf{L}=$ forewing-pad length; $\mathbf{M T L}=$ metatibial length.

Table 2: Measurements (mm) and ratios of Trioza schefferae adults $(\mathrm{N}=$ number of measured specimens)

\begin{tabular}{|lllllllll|}
\hline Males & & & \multicolumn{7}{c}{ Females } \\
Parameters & N & Min & Max & Average & N & Min & Max & Average \\
BW & 43 & 2.64 & 3.82 & 2.99 & 45 & 2.70 & 3.70 & 3.12 \\
HW & 43 & 0.58 & 0.88 & 0.71 & 45 & 0.64 & 1.00 & 0.79 \\
AL & 43 & 0.58 & 0.82 & 0.68 & 45 & 0.58 & 0.94 & 0.72 \\
F1 & 43 & 1.29 & 2.05 & 1.57 & 45 & 1.23 & 1.94 & 1.52 \\
FCL & 43 & 0.17 & 0.35 & 0.25 & 45 & 0.17 & 0.47 & 0.25 \\
WL & 43 & 0.11 & 0.23 & 0.19 & 45 & 0.11 & 0.35 & 0.19 \\
WW & 43 & 2.11 & 4.64 & 3.77 & 45 & 3.76 & 4.64 & 3.90 \\
wL & 43 & 1.11 & 2.0 & 1.40 & 45 & 1.23 & 2.17 & 1.59 \\
wW & 43 & 0.94 & 3.58 & 2.12 & 45 & 1.41 & 2.82 & 2.24 \\
MTL & 43 & 0.41 & 1.47 & 0.72 & 45 & 0.58 & 1.64 & 0.80 \\
MFL & 43 & 0.58 & 1.11 & 0.87 & 45 & 0.47 & 1.11 & 0.91 \\
\hline
\end{tabular}




\begin{tabular}{lllllllll}
\hline MPL & 43 & 0.17 & 0.41 & 0.38 & & & & \\
PL & 43 & 0.11 & 0.29 & 0.20 & & & & \\
FPL & & & & & 45 & 0.35 & 0.58 & 0.46 \\
SGPL & & & & & 45 & 0.23 & 0.47 & 0.31 \\
DAEL & 43 & 0.29 & 0.17 & 0.23 & & & & \\
BL/HW & 43 & 13.1 & 4.6 & 4.3 & 45 & 4.6 & 3.9 & 4.3 \\
BL/BW & 43 & 4.5 & 4.3 & 4.2 & 45 & 4.2 & 3.7 & 3.9 \\
AL/HW & 43 & 2.2 & 2.5 & 2.3 & 45 & 2.1 & 2.06 & 2.1 \\
F1/HW & 43 & 0.29 & 0.42 & 0.36 & 45 & 0.29 & 0.5 & 0.34 \\
AL/F1 & 43 & 7.5 & 5.8 & 6.2 & 45 & 7.2 & 4.1 & 6,0 \\
WL/HW & 43 & 3.6 & 5.6 & 5.5 & 45 & 6.4 & 4.9 & 5.4 \\
WL/WW & 43 & 1.9 & 2.3 & 2.6 & 45 & 3.0 & 2.1 & 2.4 \\
WL/wL & 43 & 2.2 & 1.2 & 1.7 & 45 & 2.6 & 1.6 & 1.7 \\
MTL/HW & 43 & 1,0 & 1.3 & 1.2 & 45 & 0.8 & 1.1 & 1.2 \\
PL/HW & 43 & 0.1 & 0.3 & 0.2 & & & & \\
FP/SGPL & & & & & 45 & 1.5 & 1.2 & 1.4 \\
& & & & & & & &
\end{tabular}

Abbreviations: $\mathbf{B L}=$ body length; $\mathbf{B W}=$ body width; $\mathbf{H W}=$ head width; $\mathbf{A L}=$ antenna length; $\mathbf{F}_{\mathbf{1}}=$ length of first antennal flagellomere; $\mathbf{F C L}=$ frontal cone length; $\mathbf{W L}=$ forewing length; $\mathbf{W W}=$ forewing width; $\mathbf{w L}=$ hindwing length; $\mathbf{w W}=$ hindwing width; $\mathbf{M T L}=$ metatibial length; $\mathbf{M F L}=$ metafemur length; $\mathbf{M P L}=$ male proctiger length; $\mathbf{P L}=$ paramere length $\mathbf{D A E L}=$ distal segment of aedeagus length; $\mathbf{F P L}=$ female proctiger length; $\mathbf{S G P L}=$ female subgenital plate length .

\section{REFERENCES}

[1] Burckhardt D., Ouvrard D., 2007.The taxonomy, biogeography and host plant relationships of jumping plant-lice (Hemiptera: Psyllidae) associated with creosote bushes (Larreaspp., Zygophyllaceae). Syst. Entomol. 32(1): 136-155.

[2] Hodkinson I.D., 1974. The biology of the Psylloidea (Homoptera): a review. Bull. Entomol. Res., 64: 325-339. 
[3] Hollis D., 1984. Afrotropical jumping plant-lice of the family Triozidae (Homoptera: Psylloidea). Bulletin of the British Museum (Natural History), Entomol. series, 49 (1): 1-103.

[4] Tamesse J.L., Burckhardt D., Dzokou V.J., Yana W., Mveyo Ndankeu Y.P., Foko Dadji G.A., Messi J., 2007. Jumping plant-lice of the family Triozidae (Hemiptera: Triozidea) from Cameroon: Biodiversity and Host Plants. J. Entomol., 4 (3): 181-193.

[5] Dzokou V.J., Tamesse J.L., Burckhardt D., 2009. Trioza messiisp.n., a new species of jumping plant-louse (Hemiptera: Triozidae) from Cameroon associated with Caloncoba welwitschii (Oliv.) Gilg. (Flacourtiaceae). Cameroon J. Exp. Biol., 05 (1): 29-36.

[6] Yana W., Mveyo NdankeuY.P., Dzokou V. J., and Tamesse J.L., 2017. Trioza kala sp.n. (Hemiptera: Triozidae), a new species of psyllid associated with Beilschmiediaobscura (Fouilloy et al., 1974) (Lauraceae) from Cameroon. J. Entomol. Zool. Studies, 5(6): 2179-2183.

[7] Hollis D., 1973. African gall bugs of the genus Phytolyma (Hemiptera, Psylloidea). Bull. Entomol. Res., 63: 143-154.

[8] Hollis D., 1987. A review of the Malvales-feeding psyllid family Carsidaridae (Homoptera). Bulletin of the British Museum (Natural History), Entomol. series, 56 (2): 87-127.

[9] Ossiannilsson F., 1992. Psylloidea (Homoptera) of Fennoscandia and Denmark. Fauna Entomologica Scandinavica, 26: 1-347.

[10] Yang, C.T., 1984. Psyllidae of Taiwan.Taiwan Museum Special Publication Series 3, 305 pp. 